Globus An International Journal of Management \& IT A Refereed Research Journal

Vol 11 / No 1 / Jul-Dec 2019 ISSN: 0975-721

\title{
DESIGNS FOR QUALITY ENRICHMENT IN HIGHER EDUCATION
}

\author{
*Dr Rajeev Kumar
}

\begin{abstract}
The paper presents and discuss about an era of academic globalization. Though internationalism in education has been age old, the current wave has a new aspect i.e. augmenting, collaboration \& cooperation. We are living in a rapidly changing time. Actually, change is the basic/fundamental rule of nature but this change is always purposeful \& provides various new opportunities \& makes a co-ordination with emerging trend. In the same way, change is also required in the form of innovations in the instructional strategies and designs, which should be fruitful \& lucrative for entire education system.
\end{abstract}

Keywords: Quality, Education, Instructional, Academic, Globalization.

\section{Introduction}

Instructional strategies that influenced teachers' attitudes toward initiating and sustaining change in their practice. Instructional strategies in the professional development course are successful in affecting teachers' attitudes toward initiating and sustaining change in their practice. However, the power of Instructional strategies to influence teachers' attitudes is not inherent in the strategy itself. The course was developed using a new model, The Reflective Conceptual Model (Ray, 2007), and followed the steps in the process. The application of the process allowed the power of instructional strategies to increase exponentially; expected to operate, including the innovations that are adopted. Some of those sources of influence (such as teacher certification boards) can demand that certain curricula be adopted, specific instructional procedures be utilized, and delineate the conditions under which candidates will be selected for entry into teacher education programs. Other sources of influence include how other professionals are prepared (e.g., case-based or problem-based learning from legal and business preparation, constructivist teaching methods derived from educational psychology). Issues involving innovation in teacher education have been studied by education researchers, reformers, and practitioners. For example, in a seminal work, Lilly (1973) wrote, "A first premise is that the technical soundness of an innovation as demonstrated by educational research is seldom necessary and never sufficient to guarantee adoption of that innovation by educational practitioners consider the success of educational innovations [between 1960-1970], some proving successful (Sesame Street) and others apparently dying on the vine (performance contracting)".

\footnotetext{
* Assistant Professor, Department of Mathematics, NRS Government College, Rohtak, Haryana, India.

Email: rajeevkumar@gmail.com
} 
Since then, some teacher educators have evaluated instructional innovation (e.g., Barrell, 1996), and in 1996, an entire issue of Teacher Education Quarterly was devoted to innovative colleges of education. Other researchers have studied team teaching in teacher education (Cruz \& Zaragosa, 1998); teacher educators' beliefs about professional development schools (De Witt, Birrell, Cook, Ostlund \&Young, 1998); alternative teacher education programs such as school-university partnerships (Benton and colleagues, 1996). However, Melvin (1993) calls for more concerted efforts to study the influence of professional studies by faculties of education on actual practice in classrooms and schools.

Kenneth Zeichner, a past president of the Teacher Education Division of the American Educational Research Association, traced the types of scholarship in which teacher educators typically engaged between 1978 and 1999. He stated that the "new scholarship in teacher education is a much richer and more varied body of inquiry than that which existed 20 years ago". In addition to studies of the nature and impact of teacher education innovative practices such as electronic technologies, field-based programs, interdisciplinary or subject specific methods courses), methodologies have included case studies, narrative and life history methods, action research, life history and autobiographical methods.

\section{Need of Innovations in Teacher Education}

The teaching and learning of education is a complex activity and many factors determine the success of this activity. The nature and quality of instructional material, the presentation of content, the pedagogic skills of the teacher, the learning environment, and the motivation of the students are all important and must be kept in view in any effort to ensure quality in teaching learning. Education in its broadest sense presupposes a better understanding of teaching and learning. On one side, teachers are supposed to be able to impart their knowledge through the many approaches, methods and techniques at their disposal. Teaching, for instance, requires a basic skill in explaining abstract concepts. Abstract thinking is one of the skills to be introduced to students at an early stage of learning this science. In India, however, studies has often been cited as a "monster" that troubles the students' progress in learning for a higher level of education. On the other, students particularly those who will continue their studies to a tertiary level are confronted with the various problems of life. They lack books, especially the translated texts, and other learning aids. Unlike in advanced countries, the students in India entirely depend on the explanation given by their teachers. This is especially true of learning as the basic science to further their studies.

In reality, there is a big chasm between teachers and students. Teachers believe that they can produce a change of behavior, as is defined in the process of learning, after explaining everything about complex concepts. Students, on the other hand, feel that they have not learned enough from their teachers. As a result, there is a kind of "tug of war" between the two parties. The question is which party should be given more treatment, the teachers or the students.

For the feasible purposes, teachers should be given more training and knowledge on how to teach. Part of the solution is that the teachers should change their perception about their students. Students are no longer "containers to be filled", instead they are curious people with much potential to learn anything new. What is needed today is the cooperation between teachers and students in finding solutions to the problems of teaching and learning. Both parties must realize the importance of sharing and exchanging experiences. Teaching must be very interesting that can help the students solve the many problems they face. Teachers can no longer boast of their overt knowledge. Students can be expected to contribute to the understanding of this science. The old saying "a teacher knows better" is no longer applicable.

Teaching students who do not have a very strong background in subject is always challenging. This experience is also extremely rewarding when these students begin enjoying the journey, which leads to mastering the concepts. The main purpose is to determine if the use of innovative methods of teaching including the technologies associated with modern computing enhances learning.

\section{Maximizing The Power of The Instrumental Strategies}

The success of the instructional strategies selected for the course in initiating and sustaining change in teachers' practice can be attributed to the design process. The complex nature of the problems generated by the research-to-practice gap in education required the creation of two theoretical frameworks for the design process. The theoretical frameworks for the course served as an organizing agent for the creation of core and structural features of the course. 
The synthesis of theories from andragogy, pedagogy, and heutagogy resulted in the development of a theoretical framework for the course that intentionally demonstrated respect for the skills and orientations that teachers bring with them. The intentional design of the course was directly responsible for overcoming four major reasons for the existence of the research-to-practice gap (a) poor communication between researchers and practitioners, (b) limited opportunities for meaningful professional development, (c) teacher beliefs and assumptions, and (d) the failure of research to produce usable interventions.

If the power to influence teachers' attitudes towards change is in the process, how do you determine the power of instructional strategies (IS ${ }^{\mathrm{X}}$ )? The analysis of the results confirmed the value of meeting learner needs (LN) and the power of attributes of innovations (IA). The results were supported by pre-existing research knowledge in the areas of professional development, instructional design, change, and educational change and were verified by the review of the literature.

\section{Conclusion}

The power of instructional strategies in the course developed for this study can be calculated by determining their degree of alignment with learner needs (LN) and attributes of innovations (IA). Specifically selecting strategies that are aligned with identified learner needs (LN) and designing learning experiences that enable participants to experience the innovation through attributes of innovations (IA) increases the power of the strategy to influence a participant's attitude toward acceptance of the innovation. The power of the instructional strategy (IS) increases through the purposeful design of the learning environment and the creation of learning experiences that maximize the effectiveness of the instructional strategies. Maximizing the power of the instructional strategies can occur through the design of both the core and structural features of the course.

The process of maximizing the power of instructional strategies (IS) will be illustrated through application of the process. The process begins by utilizing research knowledge to assist in the identification of learner needs (LN). The review of the literature uncovered the following research based learner needs: curriculum map, application of knowledge, research knowledge, collective participation, reflection, coherence, and self-directed learning. After that the instructional goal for the course is defined. The instructional goal for the course created for this study was to increase each participant's ability to plan learning environments that engage students in performance understandings that require the student to extend, synthesize, and apply what they know.

\section{References}

1. Agarwal, Nidhi and Jaiswal, Sushma, (2019). "A Study at Organizational Commitment of Educator in School". International Journal of Multidisciplinary Education and Research, 4(1); 39-41; doi: 10.5281/zenodo.3806468.

2. Agarwal, Nidhi and Pundir Neelam, (2019). "A Comparative Study of Personality Traits and Thinking Styles of ICT Users and Non Users". International Journal of Dynamic Educational Research Society, 1(1); 74-83.

3. Agarwal, Nidhi and Jaiswal, Sushma, (2018). "A Study on Job Satisfaction Among Female Teachers". Globus An International Journal of Management \& IT, 9(2); 1380-1382; doi: 10.5281/zenodo.3806127.

4. Agarwal, Nidhi and Gupta, Ruchika, (2011). "Role of Technology for the Efficiency of HR Management". Information and Communication Technology: Challenges \& Business Opportunities, (Eds. Avinash Singh, Puneet Kumar and Suresh Kumar) Excel India Publishers, Delhi, 174-176, ISBN: 978-93-81361-00-9.

5. Gupta, Ruchika and Kumar, Puneet, (2013). "Information Technology Business Value Assessment: A Case of State Bank of India". Globus: An International Journal of Management \& IT, 4(2): 30-34, ISSN:0975$721 \mathrm{X}$.

6. Agarwal, Nidhi and Naveen, (2016). "A Research Study on Effect on Teacher's Emotional Intelligence and Their SelfEfficiency in Relation to Their Competency". Globus Journal of Progressive Education. 6(2): 1-3, ISSN: 2231-1335.

7. Varma, Siddharth and Gupta, Ruchika, (2016). "Customer Perception \& Behavioral Intention to Use Biometric Enabled eBanking Services in India”. Business Analytics and Cyber Security Management in Organizations, (Eds. Rajagopal and 
Ramesh Bahl), IGI Gobal Publications, Hershey, PA, 137-146. ISBN13: 9781522509028.

8. Gutpa, Ruchika and Agarwal, S.P., (2017). "A Comparative Study of Cyber Threats in Emerging Economies". Globus: An International Journal of Management \& IT, 8(2): 24-28, ISSN:0975-721X.

9. Goyal, Ashish, (2011). "Challenges for HR Managers in Indian BPO Industry”. Globus An International Journal of Management \& IT, 2(2), ISSN: 0975-721X.

10. Santhi, V., (2012). "A Comparative Study on the Performance of Aditya Birla Group of Companies Grasim Industries \& Hindalco". Globus An International Journal of Management \& IT, 3(2); 1-6, ISSN: 0975-721X.

11. Engr., Ronald, John, C., Sayson, (2019). "Self-Efficacy in Learning C Programming Language”. Globus An International Journal of Management \& IT, 10(2); 26-31, ISSN: 0975-721X.

12. Bhawna, (2019). "How will Modern Technologies Change The Way of Teaching". Globus Journal of Progressive Education, 9(1); 26-31, ISSN: 2231-1335; doi: 10.46360/globus.220191002. 